\title{
The effects of pre-puberal environment and post-puberal blindness on maze learning'
}

\author{
Leonard Lash and Alvin G. Goldstein \\ UNIVERSITY OF MISSOURI
}

\begin{abstract}
Abstraet
After weaning, one group of rats was housed in an impoverished environment while a second group was housed in an enriched environment. At maturity, about one-half of each environment group was blinded. Subsequent performance in a Lashley Type III maze indicated that both blinding and the impoverished environment had significant deleterious effects on trials and errors to criterion. The latter measure also produced a significant Environment $\mathrm{X}$ Vision interaction.

\section{Problem}

Hebb (1947) and Hymovitch (1952) have both studied the relationship between early experience and the development of the visual modality. In both of these studies the environmental dimension was varied in the usual manner (e. g. Bingham \& Griffiths, 1952). In addition, one-half of each environment group was blinded before their eyes opened, while the other half was blinded at puberty. Hymovitch found that within blinding groups, those who had been housed in the more complex environment learned faster than those who had been housed in the less complex environment. Age at blinding did not have an effect nor did the two (environment and age of blinding) independent variables seem to interact.

The present study also faces the general question of the relationship between early experience and vision. Where the Hebb and Hymovitch papers studied the relationship between type of environment and age of blinding, this study is designed to determine whether or not blinding, after puberty, modifies the effects of pre-puberal experience on learning.
\end{abstract}

\section{Method}

Fifty-two male black-hooded rats bred and raised at the University of Missouri Psychology Department were used. Until weaning, all Ss were housed with their mother and siblings in $14 \times 14 \times 9$ in cages. After weaning, onehalf of the males in each litter were placed in an "Impoverished" environment and the other half in an "Enriched" environment. Each of the impoverished Ss lived alone in a $91 / 2 \times 7 \times 7$ in cage with the only open side facing a wall. The enriched Ss lived in groups of approximately $12 \mathrm{Ss}$ in relatively large $34 \times 31$ x 14 in cages of a design similar to that used by Schwartz (1964).

At 95 days of age, all Ss were anesthetized with pentobarbital and one-half of each environmental group was blinded by thermocautery. After blinding, all Ss were housed in individual cages. Ten days were allowed for recovery and during this period, each $S$ was weighed and handled daily.
All Ss received pre-training on a straight runway during the 9 th and 10 th post-blinding days. On the 11th, 12th, 13th, 14th, and 15th post-blinding days, 4, 5, 6, 7, 9 , and 9 training trials respectively were given on the Lashley Type III maze. This yielded a total of 40 trials in six days. The intertrial interval was $5 \mathrm{~min}$. and the reward was a paste of powdered Purina lab chow and water.

Errors were counted electrically. Each cul had a $3 \times 3$ in plate placed 1 in within the cul. Each time an S stepped on one of these plates a counter was activated. Similar plates were located in each of the correct alleys.

\section{Results and Diseussion}

The data were analyzed to determine the effects of environment and vision on trials and errors to criterion. The $\mathrm{N}$ and mean score for each of the four groups on each of these performance variables is presented in Table I. Analyses of variance for groups with unequal Ns (Walker \& Lev, 1953) were used to determine the significance of the differences in performance between the groups.

Vision and environment had significant effects on the number of trials and errors needed to reach a learning criterion of five consecutive errorless trials. The two groups which were raised in the impoverished environment required significantly more trials $(p<.01)$ and committed more $(p<.001)$ errors to reach the learning criterion than those raised in an enriched environment. The two blinded groups also required more trials $(p<.01)$ and committed more errors $(p<.001)$ to attain this criterion than the two normal groups. The Vision $\mathrm{X}$ Environment interactions were not in agreement. While the trials to criterion measure did not yield a significant interaction, the errors to criterion measure did $(p<.001)$. A plot of the mean number of errors made by each group on each training trial is shown in Figure 1.

Overall, the results of this study have borne out previous findings that both environment and vision

Table 1. The Mean Performance of Each of the Four Groups on Both of the Independent Variables

$$
\text { Group N Trials to Errors to }
$$$$
\text { Criterion Criterion }
$$

$\begin{array}{llll}\text { Enriched-Normal } & 15 & 16.9 & 60\end{array}$

$\begin{array}{llll}\text { Enriched-Blind } & 16 & 20.5 & 80\end{array}$

Impoverished-Normal $10 \quad 19.9 \quad 96$

Impoverished-Blind $\quad 11 \quad 29.3 \quad 216$




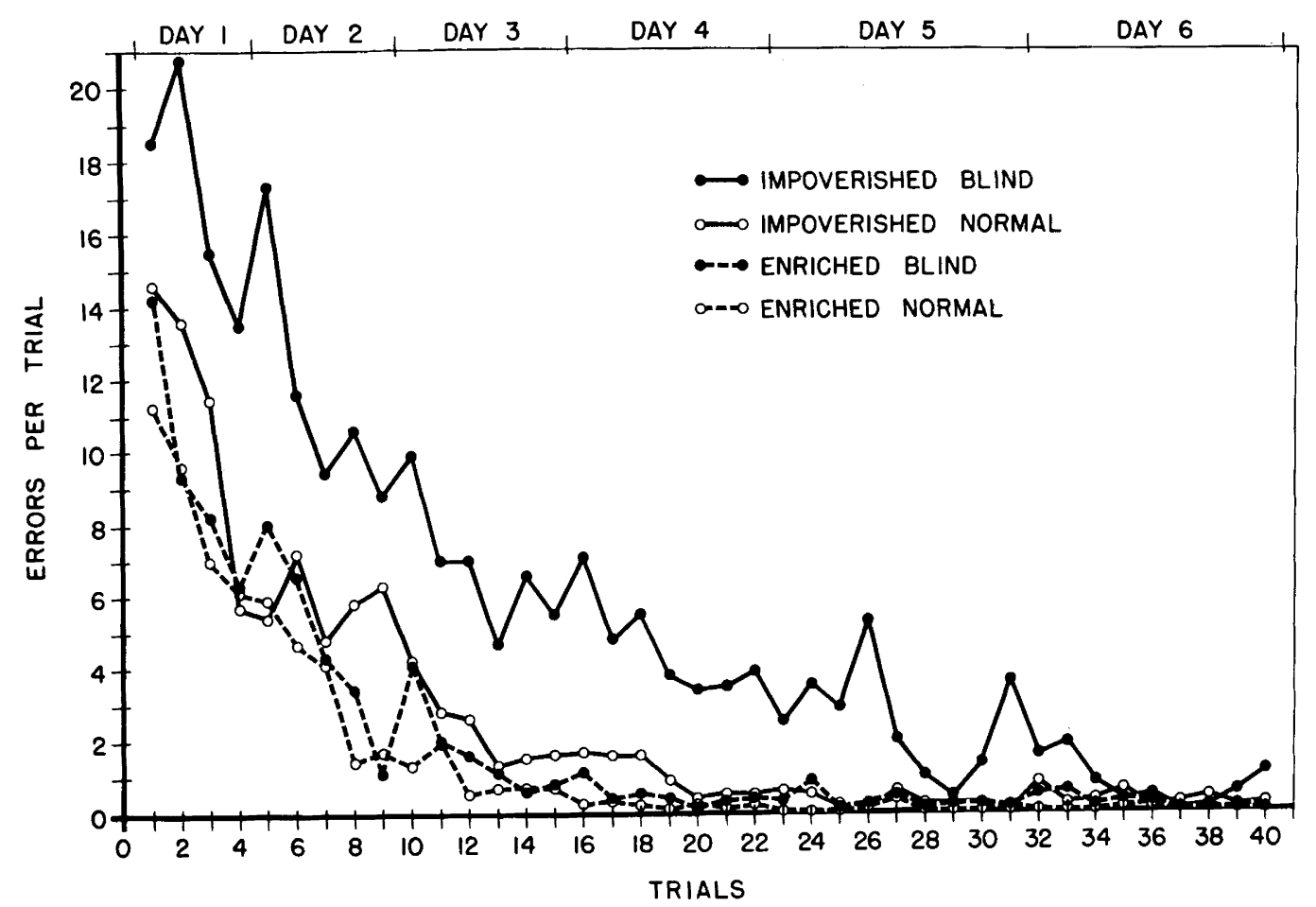

Fig. 1. Mean number of errors made by the Ss of each group on each trial.

have significant effects on learning. The consistant effect of the environmental variable on both performance measures is in full agreement with previous reports (e. g. Forgays \& Forgays, 1952). In this paper, Ss raised in an enriched environment performed better than those raised in an impoverished environment. Similarly, the effect of blinding on performance is also in agreement with earlier studies. Watson (1907), Honzik (1936), and Lashley (1943) all report that blinded rats learn more slowly than seeing rats.

These well substantiated main effects, taken together, indicate that blinding has a significant deleterious effect on the performance of both environment groups. In addition, this blindness effect does not differentially affect the performance on the trials to criterion measure of the two environmental groups. Thus, vision and environment have independent effects on the trials to criterion measure. However, the blindness and environment effects do interact on the error measure. In this case, the group raised in the impoverished environment is affected far more severely by blinding than is the group raised in the enriched environment.
References

BINGHAM, W. E., \& GRIFFITHS, W. J., JR. The effect of different environments during infancy on adult behavior in the rat. J. comp. physiol. Psychol., 1952, 45, 307-312.

FORGAYS, D. G., \& FORGAYS, J. W. The nature of the effect of free environmental experience in the rat. J. comp. physiol. Psychol., $1952,45,322-328$.

HEBB, D. O. The effects of early experience on problem solving at maturity. Amer. Psychologist, 1947, 2, 306-307.

HONZIK, C. H. The sensory basis of maze learning in rats. Comp. psychol. Monogr., 1936, 13 (Whole No. 64).

HYMOVITCH, B. The effects of environmental variations on problem solving in the rat. J. comp. physiol. Psychol., 1952, 45, 313-321.

LASHLEY, K. S. Studies of cerebral function in learning, XII. Loss of maze habit after occipital lesions in blind rats. J. comp. Neurol., 1943, 79, 431-462.

SCHWARTZ, S. Effect of neonatal cortical lesions and early environmental factors on adult rat behavior. J. comp. physiol. Psychol., $1964,57,72-77$.

WALKER, H. M., \& LEV, J. Statistical inference. New York: Ḧenry Holt, 1953.

WATSON, J. B. Kinesthetic and organic sensations: their role in the reactions of the white rat to the maze. Psychol. Rev. (Monogr. Suppl.), 1907, 8, (2), pp. vi +100 .

Note

1. This research was supported in part by National Science Foundation Grant GB-1999 to L. Lash, and in partby a grant from the University Research Council of the University of Missouri. 